\title{
Relationship between Organizational Innovativeness Types and Organizational Effectiveness in Private Universities in Iran
}

\author{
Giti Ashraf (Corresponding author) \\ Faculty of Educational Studies \\ University Putra Malaysia 43400 Serdang, Selangor, Malaysia \\ E-mail: gitiashraf@yahoo.com
}

Suhaida Abd. Kadir

Faculty of Educational Studies

University Putra Malaysia 43400 Serdang, Selangor, Malaysia

E-mail: suhaida@educ.upm.edu.my

Zaidatol Akmaliah Lope Pihie

Faculty of Educational Studies

University Putra Malaysia 43400 Serdang, Selangor, Malaysia

E-mail: zalp@educ.upm.edu.my

\author{
Abdullah Mat Rashid \\ Faculty of Educational Studies \\ University Putra Malaysia 43400 Serdang, Selangor, Malaysia \\ E-mail: abdullah@educ.upm.edu.my
}

Received: August 19, 2013 Accepted: January 29, 2014 Published: February 1, 2014

doi:10.5296/jse.v4i1.4154 URL: http://dx.doi.org/10.5296/jse.v4i1.4154 


\begin{abstract}
Empirical evidences indicate that if institutions of higher education are to survive and achieve long-run viability, they must be effective. Organizational innovativeness is viewed as an important factor for improving the organizational effectiveness in these organizations. The aim of this study was to examine the correlations between organizational innovativeness types and organizational effectiveness. The method used in the study was survey research. Based on cluster sampling method, 485 full time faculty members from Islamic Azad University, Iran, were selected as the respondents of the study. Two questionnaires were developed according to an extensive review of literature for measuring organizational innovativeness types and organizational effectiveness. The results indicated that both technical and administrative innovations positively and significantly predicted organizational effectiveness. Therefore, universities must implement administrative and technical innovations to improve organizational effectiveness. However, each type of innovativeness affects different aspects of organizational performance.
\end{abstract}

Keywords: Administrative innovation, Cameron's (1978) model, Higher education, Iran, Technical innovation 


\section{Introduction}

Organizational effectiveness is the ability of an organization to access and attract resources and consequently achieve its aims (Mcluhan, 2006). Accountability and institutional effectiveness are expected from universities for several reasons, including the rising student enrolments, increasing costs of education, decreasing research grants, diminishing learning-teaching resources, as well as growing needs for skilled workers and economic development (Burke, 2005; Skolits \& Graybeal, 2007). According to the literature review, there are quite a few studies on the relationship between organizational innovativeness and organizational effectiveness (Subramanian \& Nilakanta, 1996). Some studies have shown a positive relation between these two variables (Gopalakrishnan, 2000; Lin, 2006; Tajeddini, 2011; Wang, 2005).

Organizational innovativeness means the capability of an organization for innovation and its active ability to put new opinions, technology or products into practice (Lin, 2006). Innovation helps higher education organizations to grow and maintain their roles in changes. It helps them initiate cooperation of researchers and professors that can bridge the gap between research, training and innovation (Ghorchian \& Salehi, 2005).

A key to achieving organizational effectiveness is faculty support and participation in all institutional effectiveness initiatives. Despite their multiple roles and responsibilities, faculty members, in any type of university, engage in three primary types of activity, including teaching, research, and service (Middaugh \& Isaacs, 2003). Clearly, faculty involvement in effective institutional activities requires examination of faculty perceptions to improve institutional productivity, an idea earlier supported by K. M. Schilling and K. L. Schilling (1998).

Therefore, it seems that investigation of the relationship between organizational innovativeness and organizational effectiveness in universities based on faculty members' perception can help senior administrators and university policy makers. The findings of such an investigation can lead to their better understanding of a factor related to organizational effectiveness. Awareness of this factor can help administrators improve organizational performance.

\section{Organizational Innovativeness Types}

This study utilizes two innovation types, namely technical innovation and administrative innovation that are most widely used in conceptualizing and operationalizing innovation (Damanpour, 1987; Jaskyte, 2002; Obenchain, 2002). As Damanpour, Walker, and Avellaneda (2009) state, "administrative innovations pertain to changes in the organization's structure and processes, administrative systems, knowledge used in performing the work of management, and managerial skills that enable an organization to function and succeed by using its resources effectively" (p. 655).

In contrast, technical innovation is defined as the implementation of a service, program, or product that is new to the prevailing organizational practice (Jaskyte, 2011). Technical innovation can lie in: (1) the unprecedented new technological content present in the newly 
introduced products or (2) the process that uses new instruments of the technological development (Wang \& Ahmad, 2004). In the present study, the organizational innovativeness refers to the frequency of times each type of innovation (technical and administrative) is actually implemented in the organization during the past 3-year-long period (Jaskyte, 2002; Obenchain, Johenson, \& Dion, 2004).

\section{Organizational Effectiveness}

In an effort to address the need for a meaningful model for effectiveness in educational institutions, Cameron (1978) identified nine dimensions of organizational effectiveness. These dimensions can be used to evaluate the performance of all forms of postsecondary institutions.

The first four dimensions focus on students, including students' educational satisfaction, professional development, academic development, and personal development. Effectiveness in the above-mentioned dimensions means to determine to what extent the students are satisfied with their studies and to what extent they are professionally, scientifically, and individually proficient.

The fifth dimension in organizational effectiveness is the satisfaction of the faculty and the administrators with their employment. It indicates that the members of the faculty are satisfied with the situations they are in. The next dimension is progress in profession and efficiency which the faculty bears. It means to identify how much the faculty members have improved in their profession and how well the faculty has gained progress. Furthermore, the incentives which the institution provides for the members can be identified, too. The seventh dimension is system openness and community relationship. It indicates the focus on the relationship and compatibility with and working inside and outside the organization. The next dimension is the capability in attracting resources. It deals with identifying to what extent the organization has access to outside resources such as financial resources and legal support. This dimension also seeks to identify to what extent the organization can attract well-qualified students and faculty members. The last dimension is organizational health that will determine to what extent the organization supports its staff and faculty members. In this study organizational effectiveness is studied based on nine dimensions of Cameron's (1978) model mentioned above. The capacity of the model is well documented and seems quite suitable to be used for higher education studies (Ashraf \& Kadir, 2012; Kwan \& Walker, 2003; Smart, 2003).

\section{Aim and Questions of the Study}

The aim of this study was to explore the relationship between organizational innovativeness types and organizational effectiveness in private universities in Iran as perceived by the faculty members. This study pursued the following questions:

- Is there any significance relationship between organizational innovativeness types and organizational effectiveness in private universities as perceived by the faculty members? 
- Which type of organizational innovativeness is the best predictor of organizational effectiveness in private universities as perceived by the faculty members?

\section{Methodology}

\subsection{Design and Participants}

Based on its research objectives, this study follows a quantitative method in which the survey research technique is used. Using one-stage cluster sampling the five branches were selected among 24 branches of Islamic Azad University, Pars Province, Iran by simple random sampling. Then, all the full time faculty members within these five branches were included in the sample. The total number of faculty members in the selected branches was 485 lecturers. The actual size of the respondents who completed the questionnaire comprised 369 faculty members (a response rate of $76 \%$ ). The respondents received the questionnaires in person in their colleges, classes and offices.

\subsection{Instrument}

For measuring organizational innovativeness types, a 17- item questionnaire was developed, based on review of the literature and discussions with five experts. The respondents would determine the frequency of implementation of each innovation activity in the last three years, following a Likert scale of 1 (rarely) to 5 (very frequently). The other instrument was developed by the researchers for measuring organizational effectiveness in higher education institutes in Iran. It was an 81-item questionnaire developed based on an extensive review of the literature and Cameron's (1978) model.

\subsection{Validity and Reliability}

The face validity and content validity of the research instrument was checked in a pilot study by some experts. The reliability of the questionnaire was measured by Cronbach's alpha based on 50 faculty members' responses. The coefficients for the technical innovation (.774) and administrative innovation (.748) results indicated acceptable internal consistency, according to George and Mallery's (2003) rules of thumb for Likert-type scales. The coefficient for organizational effectiveness was .958, which indicates excellent internal consistency of the instrument. Table 1 shows the reliability estimates for the study variables from the pilot test.

Table 1. Reliability estimates for the organizational innovativeness types and organizational effectiveness from the pilot test $(n=50)$

\begin{tabular}{lcc}
\hline scale & Number of items & Cronbach's Alpha \\
\hline Technical innovation & 9 & .774 \\
Administration innovation & 8 & .748 \\
Organizational effectiveness & 81 & .958 \\
\hline Total items & 98 & \\
\hline
\end{tabular}

Moreover, the results of item analysis indicated no item-total correlation of less than .30, 
which meant that all items were correlated very well with the scales (Field, 2009; Leech, Barrett \& Morgan, 2008).

Then, a principal component factor analysis with varimax rotation was conducted to assess the construct validity of research instrument upon completion of the final data collection. In reference to Hair, et al (2006), since the number of innovativeness types and organizational effectiveness dimensions in this study have been reported in a number of other studies in the domain of higher education (e.g. Cameron, 1978; Dela Cruz, 2011; Obenchain, 2002), the number of factors is already known. For each of the two innovativeness subscales and nine effectiveness subscales, one component was extracted. It was consist with the number of factors that were found in previous studies.

Based on results of rotated component matrix, there were two subscales of technical and administrative innovations for organizational innovativeness scale. Both factor loadings were .895 . In addition, there were nine subscales for organizational effectiveness scale in the present study. Their factor loadings were ranged between .979 and .913 . In other words, each subscale was unidimensional. These results are shown in Table 2.

Table 2. Factor loading for organizational innovativeness types and organizational effectiveness dimensions $(n=369)$

\begin{tabular}{lcc}
\hline \multicolumn{3}{c}{ Organizational innovativeness } \\
\hline Factors & Number of items & Factor loading \\
Technical innovation & 9 & .895 \\
Administration innovation & 8 & .895 \\
\hline \multicolumn{4}{l}{ Organizational effectiveness } & \\
\hline Factors & Number of items & Factor loading \\
Student educational satisfaction & 8 & .965 \\
Student academic development & 8 & .938 \\
Student career development & 10 & .936 \\
Student personal development & 10 & .934 \\
Faculty employment satisfaction & 9 & .930 \\
Professional development and quality of faculty & 10 & .913 \\
System openness and community interaction & 9 & .960 \\
Ability to acquire resources & 10 & .965 \\
Organizational health & 7 & .979 \\
\hline
\end{tabular}

\section{Findings}

\subsection{Research Question 1}

In order to answer the first research question, Pearson's product moment correlations (r) were computed between the two organizational innovativeness types and organizational 
effectiveness. The results in Table 3 indicate medium significant positive correlations among the two organizational innovativeness types of technical $(\mathrm{r}=.452)$ and administrative $(\mathrm{r}$ $=.460$ ) with organizational effectiveness according to Cohen's (1992) guidelines.

Table 3. Means, standard deviations, and correlations for organizational effectiveness and independent variables $(\mathrm{n}=369)$

\begin{tabular}{lcccc}
\hline Variable & $\mathrm{M}$ & $\mathrm{SD}$ & 1 & 2 \\
\hline Organizational effectiveness & 3.130 & .271 & $.452^{*}$ & $.460^{*}$ \\
Independent variables & & & & \\
\hline 1. Technical innovation & 3.110 & .615 & & \\
2. Administrative innovation & 3.094 & .690 & & \\
\hline
\end{tabular}

$* \mathrm{P}<.001$

\subsection{Research Question 2}

A simultaneous multiple regression was conducted to determine the best linear combination of technical innovation and administrative innovation for predicting organizational effectiveness. Table 4 indicates that this combination of variables significantly predicts organizational effectiveness, $\mathrm{F}(2,366)=55.059, \mathrm{p}<.0001$, with two variables significantly contributing to the model. The adjusted $\mathrm{R}$ squared value was .227 . This indicates that $22.7 \%$ of variation in the organizational effectiveness was accounted by the model. The beta weights, presented in Table 4 show that the largest beta coefficient is .274 which is for administrative innovation. The Beta value for technical innovation is the second highest (.233). According to $\mathrm{B}$ weights, the regression equation is as follows:

Organizational effectiveness $=.103$ Technical innovation +.108 Administrative innovation + 2.477

Table 4. Estimates of Coefficients for the Model $(\mathrm{N}=369)$

\begin{tabular}{lccccc}
\hline Variables & $\mathrm{B}$ & $\mathrm{SEB}$ & $\beta$ & $\mathrm{t}$ & $\mathrm{p}$ \\
\hline Technical innovation & .103 & .034 & .233 & 3.062 & .002 \\
Administrative innovation & .108 & .030 & .274 & 3.610 & .000 \\
Constant & 2.477 & .065 & & 38.251 & .000 \\
\hline
\end{tabular}

Notes: $\mathrm{R}=.481 ; \mathrm{R}^{2}=.231 ; \mathrm{Adj} . \mathrm{R}^{2}=.227$

\section{Discussion}

Although innovation is risky, and its success is not guaranteed (Damanpour et al., 2009), a number of researchers over time have demonstrated a positive relationship between organizational innovativeness and organizational performance (Aragon-Correa, Garcia-Morales \& Cordon-Pozo, 2007; Ho, 2011; Orfila-Sintes \& Mattsson, 2009; Kasim \& Noh, 2012).

The findings of the present study indicate that organizational effectiveness is predicted by 
both technical innovation and administrative innovation. In this respect, Damanpour et al. (2009) recognized that there is a negative relationship between focus on adopting a definite type of innovation over a period of time and performance. They maintained that there is a balanced operation of the technical and social systems in effective organizations. More specifically, the adoption of both technical and administrative innovations is of equal priority. In the educational context, a study by Liaw, Huang, and Chen (2007) indicated that proper availability of new technical resource and administrative support positively influence students' satisfaction towards learning

As stated by Roberts and Amit (2003) as well as Damanpour and Daniel Wischnevsky (2006), while there are inadequate external sources along with an environmental force for making change, senior executives and managers consider innovation as something quite required in order to gain and improve organizational effectiveness. Thus, the implementation of every type of innovation will be improved and promoted because innovation is supposed to be indispensable for realizing performance objectives.

In this line, Chen, Liu, and Wu (2009) found that organizational performance is significantly related to technical and administrative innovation. They concluded that organizations should both enhance administrative and technical innovations. If organizations implement technical innovation, while neglecting administrative innovation, it is difficult to achieve the effect of technical innovation. Therefore, organizations must implement administrative and technical innovation simultaneously to achieve better organizational performance.

The findings of the two research questions showed that the organizational innovativeness types have direct correlations with organizational effectiveness. Therefore, academic administrators should continuously be open to new ideas, processes, and products. Although managers often assume that innovation is an expensive and risky effort (Tajeddini, 2011), the present study suggests that in the context of private universities, applying diverse types of innovations serve as factors that can enhance organizational effectiveness.

\section{Conclusion}

The objective of this study was to determine the organizational innovativeness type that best predicts the organizational effectiveness in private universities in Iran as perceived by the faculty members. The statistical findings revealed that both administrative and technical innovations were positive and significant predictors for organizational innovativeness.

The results illustrated that adoption of the two types of innovation does seem to be organizationally anchored and subject to private universities in Iran. Drawing on Kimberly \& Evanisko (1981), the adoption of technical innovations can be seen as one vehicle for both solving increasingly complex and non-routine problems in the technical core and enhancing the attractiveness of the private universities for faculty members as a place to teach students.

In the case of administrative innovation, the adoption of innovation requires various skills in managing the adoption process in private universities. For instance: creating a climate for innovation, integrating the innovation into existing organizational processes, maintaining a sense of urgency to enable successful implementation and facilitating its use by 
organizational members (Damanpour \& Schneider, 2009). Therefore, both organizational innovativeness types need to be strengthened within private universities in Iran in order to enhance the effectiveness of universities.

\section{References}

Aragon-Correa, J. A., Garcia-Morales, V. J., \& Cordon-Pozo, E. (2007). Leadership and organizational learning's role on innovation and performance: lessons from Spain. Industrial marketing management, 36(3), 349-359. http://dx.doi.org/ 10.1016/j.indmarman.2005.09.006

Ashraf, G., \& Kadir, S. A. (2012). A review on the models of organizational effectiveness: a look at Cameron's model in higher education. International education studies, 5(2), 80-87. http://dx.doi.org/10.5539/ies.v5n2p80

Burke, J. C. (2005). Achieving accountability in higher education: balancing public, academic, and market demands. San Francisco, CA: Jossey-Bass.

Cameron, K. S. (1978). Measuring organizational effectiveness in institutions of higher education. Administrative science quarterly, 23, 604-632. http://dx.doi.org/10.2307/2392582

Chen, J., Liu, Z. C., \& Wu, N. Q. (2009). Relationships between organizational learning, innovation and performance: an empirical examination. In Information Management, Innovation Management and Industrial Engineering, 2009 International Conference on (Vol. 3, pp. 488-492). IEEE. http://dx.doi.org/10.1109/ICIII.2009.427

Cohen, J. (1992). Methods in psychology. A power primer. Psychological Bulletin, 112(1), 155-159. http://dx.doi.org/10.1037/0033-2909.112.1.155

Damanpour, F. (1987). The adoption of technological, administrative and ancillary innovations: impact of organizational factors. Journal of management, 13, 675-688. http://dx.doi.org/ 10.1177/014920638701300408

Damanpour, F., \& Daniel Wischnevsky, J. (2006). Research on innovation in organizations: distinguishing innovation-generating from innovation-adopting organizations. Journal of engineering and technology management, 23(4), 269-291. http://dx.doi.org/10.1016/j.jengtecman.2006.08.002

Damanpour, F., \& Schneider, M. (2009). Characteristics of innovation and innovation adoption in public organizations: Assessing the role of managers. Journal of public administration research and theory, 19(3), 495-522. http://dx.doi.org/10.1093/jopart/mun021

Damanpour, F., Walker, R. M., \& Avellaneda, C. N. (2009). Combinative effects of innovation types and organizational performance: a longitudinal study of service organizations. Journal of management studies, 46(4), 650-675. http://dx.doi.org/10.1111/j.1467-6486.2008.00814.x

Dela Cruz, W. S. (2011). The roles of organizational culture, management strategy, and decision-making process on institutional effectiveness at a four-year public higher education institution. (Order No. 3489427, The University of Texas at San Antonio). ProQuest 
Dissertations and Theses, 290-290. Retrieved from http://search.proquest.com/docview/916624460?accountid=27932. (916624460).

Field, A. (2009). Discovering statistics using SPSS (and sex and drugs and rock ' $n$ ' roll). Sage publications.

George, D., \& Mallery, P. (2003). SPSS for windows step by step: A simple guide and reference. 11.0 update (4th ed.). Boston: Allyn \& Bacon.

Ghorchian, N., \& Salehi, M. (2005). Designing a model to establish providence in Islamic Azad University. Khorasgan Islamic Azad University's journal of knowledge and research, 2, 1-22. (Persian)

Gopalakrishnan, S. (2000). Unraveling the links between dimensions of innovation and organizational performance. The journal of high technology management research, 11(1), 137-153. http://dx.doi.org/10.1016/S1047-8310(00)00024-9

Hair, J. F., Black, W. C., Babin, B. J., Anderson, R. E., and Tatham, R. L. (2006). Multivariate data analysis (6 Ed.). NJ: Pearson.

Ho, L. A. (2011). Meditation, learning, organizational innovation and performance. Industrial $\begin{array}{lllll}\text { management } \quad \& \quad \text { data } & \text { systems, } & 111(1), & 13-131 .\end{array}$ http://dx.doi.org/10.1108/02635571111099758

Jaskyte, K. (2002). Organizational culture and innovation in nonprofit human service organizations. (Order No. 3067285, The University of Alabama). ProQuest Dissertations and Theses, 126-126 p. Prod.academic_MSTAR_304797931. Retrieved from http://search.proquest.com/docview/304797931?accountid=27932.

Jaskyte, K. (2011). Predictors of administrative and technological innovations in nonprofit $\begin{array}{llll}\text { organizations. } \quad \text { Public } \quad \text { Administration } & \text { Review, }\end{array}$ http://dx.doi.org/10.1111/j.1540-6210.2010.02308.x

Kasim, R. S. R., \& Noh, I. (2012). The impact of organizational innovativeness on the performance of the university: An analysis among selected Malaysian private universities. In Innovation Management and Technology Research (ICIMTR), 2012 International Conference on (pp. 1-5). IEEE. http://dx.doi.org/ 10.1109/ICIMTR.2012.6236350

Kimberly, J. R., \& Evanisko, M. J. (1981). Organizational innovation: The influence of individual, organizational, and contextual factors on hospital adoption of technological and administrative innovations. Academy of management journal, 24(4), 689-713. http://dx.doi.org/10.2307/256170

Kwan, P., \& Walker, A. (2003). Positing organizational effectiveness as a second-order construct in Hong Kong higher education institutions. Research in Higher Education, 44(6), 705-726. http://dx.doi.org/10.1023/A:1026179626082

Leech, L., Barrette, K. C., \& Morgan, G. (2008). SPSS for introductory statistics: Use and interpretation. Lawrence Erlbaum Associates, New York. 
Lin, Y. (2006). An examination of the relationships between organizational learning culture, structure, organizational innovativeness and effectiveness: Evidence from taiwanese organizations. (Order No. 3243353, University of Minnesota). ProQuest Dissertations and Theses, 143-143 p. Prod.academic_MSTAR_305306290. Retrieved from http://search.proquest.com/docview/305306290?accountid=27932.

Mcluhan, M. (2006). Towards an effective theory of organizational effectivenes. Retrieved from http://.whatisthemessage.blogspot.com/2006_03_01_archive.html

Middaugh, M., \& Isaacs, H. (2003). Describing faculty activity and productivity for multiple audiences. The primer for institutional research, 24-47.

Obenchain, A. M. (2002). Organization culture and organizational innovation in not-for-profit, private and public institutions of higher education. (Order No. 3039605, Nova Southeastern University). ProQuest Dissertations and Theses, 272-272 p. Retrieved from http://search.proquest.com/docview/251795245? accountid=27932.

(prod.academic_MSTAR_251795245).

Obenchain, A. M., Johenson, W. C., \& Dion, P. A. (2004). Institutional types, organizational cultures, and innovation in Christian colleges and universities. Christian higher education, 3(1), 15-39. http://dx.doi.org/10.1080/15363750490264870

Orfila-Sintes, F., \& Mattsson, J. (2009). Innovation behavior in the hotel industry. Omega, 37(2), 380- 394. http://dx.doi.org/ 10.1016/j.omega.2007.04.002

Roberts, P. W., \& Amit, R. (2003). The dynamics of innovative activity and competitive advantage: The case of Australian retail banking, 1981 to 1995.Organization science, 14(2), 107-122. http://dx.doi.org/ 10.1287/orsc.14.2.107.14990

Schilling, K. M., \& Schilling, K. L. (1998). Proclaiming and Sustaining Excellence: Assessment as a Faculty Role. ASHE-ERIC Higher Education Report, 26(3). ERIC Clearinghouse on Higher Education, One Dupont Circle, NW, Suite 630, Washington, DC 20036-1183.

Skolits, G. J., \& Graybeal, S. (2007). Community college institutional effectiveness perspectives of campus stakeholders. Community college review, 34(4), 302-323. http://dx.doi.org/10.1177/0091552106299493

Smart, J. C. (2003). Organizational effectiveness of 2-year colleges: The centrality of cultural and leadership complexity. Research in Higher Education, 44(6), 673-703. http://dx.doi.org/10.1023/A:1026127609244

Subramanian, A., \& Nilakanta, S. (1996). Organizational innovativeness: exploring the relationship between organizational determinants of innovation, types of innovations, and measures of organizational performance. Omega, 24(6), 631-647. http://dx.doi.org/10.1016/S0305-0483(96)00031-X

Tajeddini, K. (2011). The effects of innovativeness on effectiveness and efficiency. Education, business and society: contemporary Middle Eastern issues, 4(1), 6-18. 
http://dx.doi.org/10.1108/17537981111111238 2014, Vol. 4, No. 1

Wang, C. L., \& Ahmed, P. K. (2004). The development and validation of the organisational innovativeness construct using confirmatory factor analysis. European Journal of Innovation Management, 7(4), 303-313. http://dx.doi.org/ 10.1108/14601060410565056

Wang, Z. (2005). Organizational effectiveness through technology innovation and HRM strategies. International journal of manpower, 26(6), 481-487. http://dx.doi.org/10.1108/01437720510625403 